\title{
Primary ovarian lymphoma detected during tubal ligation
}

\author{
Engin Kelkitli*, Memiş Hilmi Atay ${ }^{\mathrm{b}}$, Bahiddin Yılmaz ${ }^{\mathrm{c}}$, Levent Yıldız ${ }^{\mathrm{d}}$, Mehmet Turgut ${ }^{\mathrm{e}}$ \\ ${ }^{a}$ Department of Hematology, Erzurum Research and Training Hospital, Erzurum, Turkey \\ ${ }^{b}$ Department of Hematology, Van Research and Training Hospital, Van, Turkey \\ ${ }^{c}$ Department of Oncology, Faculty of Medicine, Ondokuz Mayı University, Samsun, Turkey \\ ${ }^{d}$ Department of Pathology, Faculty of Medicine, Ondokuz Mayls University, Samsun, Turkey \\ 'Department of Hematology, Faculty of Medicine, Ondokuz Mayıs University, Samsun, Turkey
}

\begin{tabular}{|c|c|}
\hline ARTICLE INFO & ABSTRACT \\
\hline Article History & Lymphomatous involvement of the ovary is rare. Involvement is either primary or \\
\hline Received $\quad 05 / 03 / 2013$ & secondary. The most common clinical features are abdominal and pelvic complaints. We \\
\hline Accepted $\quad 04 / 05 / 2013$ & $\begin{array}{l}\text { here present a case of a } 38 \text { years old woman without any symptoms, that we have found } \\
\text { incidentally, a rare case of primary ovarian lymphoma. }\end{array}$ \\
\hline
\end{tabular}

* Correspondence to:

J. Exp. Clin. Med., 2013; 30:197-199

Engin Kelkitli

Department of Hematology,

Erzurum Research and Training Hospital,

Erzurum, Turkey

e- mail: ekelkitli@gmail.com

\section{Keywords:}

Incidentally

Lymphoma

Ovary

Tubal Ligation

\section{Introduction}

Ovarian involvement of Non-Hodgkin's lymphoma (NHL) is usually secondary, and is seen as a part of systemic disease. Primary ovarian involvement is extremely rare. While secondary cases are well-defined, we have limited information about the primary cases (Vang et al., 2001). Primary ovarian lymphomas are $1.5 \%$ of all ovarian neoplasms, and $0.5 \%$ of all the NHL's (Dimopoulos et al., 1997). The most common symptoms and finds are pelvic pain, and pelvic masses. Fox et al. reported that for diagnosis of primary lymphoma of the genital tract, cases should have certain criteria. These criteria are a) lymphoma at diagnosis, only to be limited to that region b) the absence of any infiltration of atypical cells in the peripheral blood and bone marrow, and c) between the diagnosis of genital tract lymphoma and secondary foci detected there must be at least a few months (Fox et al., 1988).

Our case is of primary ovarian involvement, without any pelvic symptoms, that have been detected incidentally. Since this situation is seen rarely we discussed in light of the literature.

\section{Case}

A thirty-eight years old woman without known disease refers to a hospital for tubal ligation. During tubal ligation operation in the hospital the left ovarian mass was identified and left salpingoopherectomy was performed. Patient who was operated in gynecology and obstetrics department was referred to the hematology department. Left oophorectomy biopsy tissue sections showed whole atypical lymphoid cells infiltrating the tumoral formation. Immunohistochemical study of tumor cells, CD20, LCA-positive, inhibin, CD117, and PLAP negative stained. (Fig. 1, 2, 3). Diagnosis was reported as diffuse large B-cell lymphoma.

There was no peripheral lymphadenopathy on physical examination. Abdominal, thoracic, and pelvic MRI was normal. CA 125 was also normal. There was no infiltration of bone marrow aspiration and biopsy. There was also no accumulation of FDG in PET CT. The patient was staged IE according to Ann Arbor staging system. The patient was administered four cycle of R-CHOP regimen (Rituximab 375 $\mathrm{mg} / \mathrm{m}^{2} \mathrm{~d}$, Cylophosfamide $75 \mathrm{mg} / \mathrm{m}^{2} \mathrm{~d}$, Doxorubucin $50 \mathrm{mg} /$ 


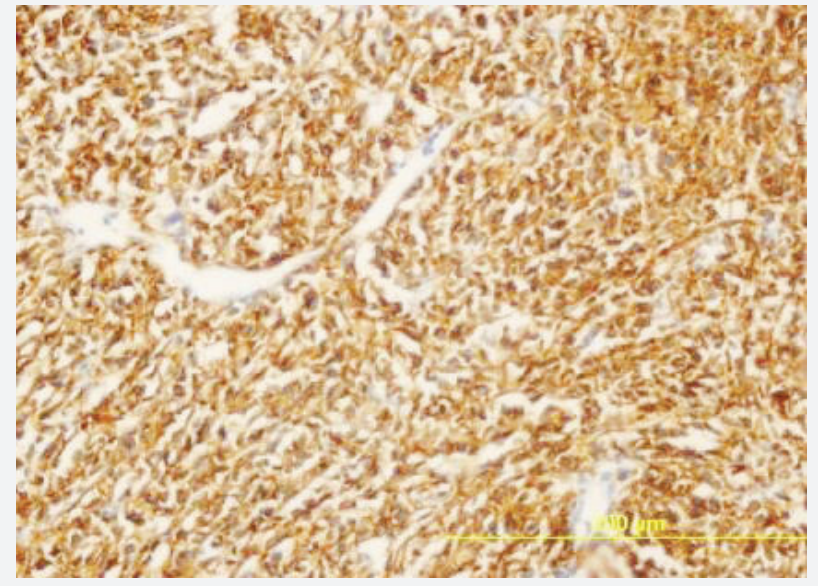

Fig. 1. Immunohistochemical study of the tumor cells, with CD20. Tumor cells stained with monoclonal antibodies against B-cell surface marker (immunohistochemical staining for CD20, original magnification : 400X)

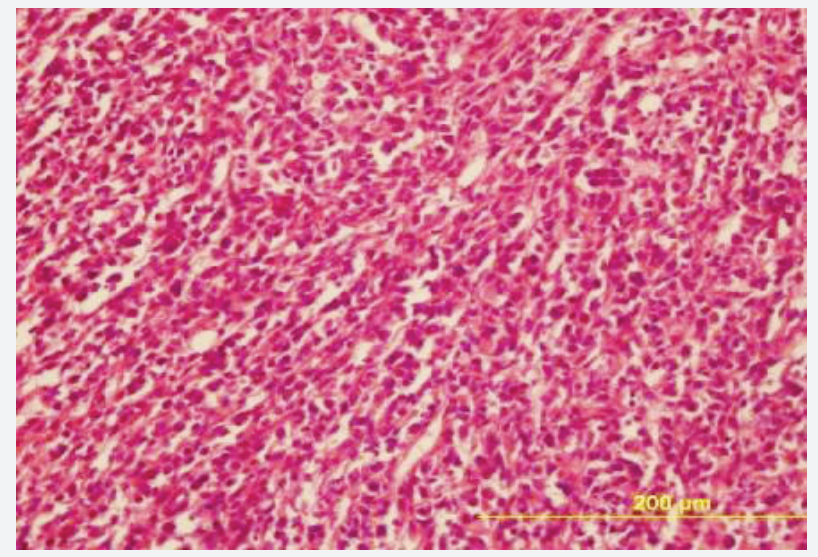

Fig. 2. Histopathological study of the tumor cells, hematoxylin and eosin. Tumor cells comprise monotonous lymphoid cells (hematoxylin and eosin staining, original magnification : 400X)

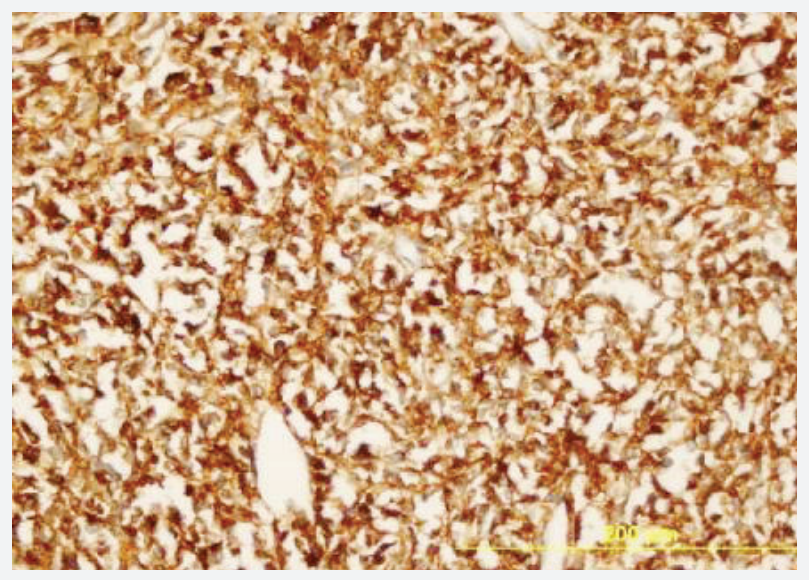

Fig. 3. Immunohistochemical study of the tumor cells, with LCA. Tumor cells are positive for LCA (immunohistochemical staining for LCA, original magnification : 400X)

$\mathrm{m}^{2} \mathrm{~d}$, Vincristine1,4 mg/dl d, metilprednisolon $80 \mathrm{mg} \mathrm{d} \mathrm{1-5);}$ 12 months after surgery, she remains disease free.

\section{Discussion}

Ovarian lymphoma is extremely rare and ovarian involvement is almost always indicate systemic disease. It is usually in the form of non-Hodgkin's lymphoma. The most common diffuse large B-cell lymphoma, Burkitt's lymphoma and follicular lymphoma types are seen (Monterroso et al., 1993; Dimopoulos et al., 1997). Very rarely, precursor B-cell lymphoblastic lymphomas have been reported (Iyengar et al., 2004). Clinical findings are nonspecific, patients with primary ovarian lymphoma usually present with complaints of pain, swelling and pelvic mass. In some patients, ascites and high levels of CA 125 can be found (Vang et al., 2001; Perlman et al., 2005). In our case, primary ovarian lymphoma has been identified incidentally when there were no symptoms. In the study of Wang and colleagues in the clinicopathological examination of 8 patients they have detected primary ovarian lymphoma incidentally in 3 patients, 2 of these patients were diagnosed during total abdominal hysterectomy and bilateral salpingoopherectomy and one was diagnosed during the excision of endometriotic cyst (Vang et al., 2001). Our case had been identified during the tubal ligation.

Primary ovarian lymphoma may occur at any age but more often effects women in their 40s. The average age of the various series of primary genital lymphoma are 47 (Vang et al., 2001), and 41.8 (Monterroso et al., 1993). The mean tumor diameter of $13.3 \mathrm{~cm}$ (Vang et al., 2001) have been reported.

Bilateral ovarian involvement is seen in approximately $40-50 \%$ of the patients. The involvement of the right ovary is usually primary, while it is secondary in the left ovary (Kosari, 2005). İ a study of Monterosso et al. (1993) in series of 39 cases $60 \%$ ( 24 patients) was found to have bilateral involvement.

Although it is seen more often in the right ovary, our patient had involvement of the left ovary. There was also no involvement of the right ovary.

Also in our case, after the pathological diagnosis, in the tests made for staging and, abdominal and thoracic MRI, lymphadenopathy was not detected in another region. There was no infiltration of the bone marrow aspiration and biopsy.

Other genital tract neoplasms in the differential diagnosis should not be forgotten. In the differential diagnosis immunohistochemical studies are helpful. LCA indicates that the neoplastic infiltrate is lymphoid. In addition, CD19 and CD20 are $\mathrm{B}$ cells phenotype; CD3, and CD5 are T-cell phenotype immune predictors (Vang et al., 2001).

In our case, LCA positivity demonstrated the neoplastic cells of lymphoid origin and CD20 positivity demonstrated the B-cell origin.

With all of these features our patient with the diagnosis of primary ovarian lymphoma received 4 cycles of R-CHOP chemotherapy. Twelve months after surgery, she remains disease free.

\section{Conclusion}

Primary ovarian malignant lymphoma is rare. Involvement of lymphoma can be seen in the ovary at an early stage without mass and complaints of pelvic pain. In these cases, staging should be done as in nodal lymphoma and treatment should be given according to the type of lymphoma. 


\section{REFERENCES}

Dimopoulos, M.A., Daliani, D., Pugh, W., Gershenson, D., Cabanillas, F., Sarris, A.H., 1997. Primary ovarian non-Hodgkin’s lymphoma: Outcome after treatment with combination chemotherapy. Gynecol. Oncol. 64, 446-450.

Fox, H., Langley, F, A., Govan, A.D., Hill, A.S., Bennett, M.H., 1988. Malignant lymphoma presenting as an ovarian tumour: A clinicopathological analysis of 34 cases. Br. J. Obstet. Gynaecol. 95, 386-390.

Iyengar, P., Ismiil, N., Deodhare, S., Precursor, B., 2004. Cell lymphoblastic lymphoma of the ovaries: An immunohistochemical study and review of the literature. Int. J. Gynecol. Pathol. 23, 193-197.

Kosari, F., Daneshbod, Y., Parwaresch, R., Krams, M., Wacker, H.H., 2005. Lymphomas of the female genital tract: A study of 186 cases and review of the literature. Am. J. Surg. Pathol. 29, 1512-1520.

Monterroso, V., Jaffe, E.S., Merino, M.J., Medeiros, L.J., 1993. Malignant lymphomas involving the ovary. A clinicopathologic analysis of 39 cases. Am. J. Surg. Pathol. 17, 154-170.

Perlman, S., Ben-Arie, A., Feldberg, E., Hagay Z., 2005. Non-Hodgkin's lymphoma presenting as advanced ovarian cancer-a case report and review of literature. Int. J. Gynecol. Cancer. 15, 554-557.

Vang, R., Medeiros, L.J., Warnke, R.A., Higgins, J.P., Deavers, M.T., 2001. Ovarian non-Hodgkin's lymphoma: A clinicopathologic study of eight primary cases. Modern Pathology. 14, 1093-1099. 